\title{
Pollution and People
}

\section{Risks of low-level radiation-the evidence of epidemiology}

\author{
DAPHNE GLOAG
}

The paradox of ionising radiation is that we probably know more about it than about any other environmental agent yet are still uncertain of the total extent of its risks at low levelsindeed, out of the welter of data support can easily be found for opposing points of view. The main worry stems from the belief that for most long-term effects there is no threshold below which radiation is completely safe. ${ }^{12}$ The so-called nonstochastic effects such as haematological damage and damage to skin and lens, which depend on cell killing, will be found in everyone given a high enough dose of radiation but in no one below a certain threshold dose, at least for low-LET radiation (see box). The stochastic effects of cancer and genetic abnormality, however, which derive from damage to the cell nucleus, will occur with a smaller and smaller probability as the dose decreases-but few scientists now believe that the probability ever reaches zero. Risk estimates for cancer are more firmly based on human data than those for genetic defects and are the main subject of this article.

\section{Dose-response models}

It is remarkably difficult to decide whether the extra cases of cancer and genetic defect likely to result from very low levels of radiation are really negligible. Apart from the difficult social judgment of what is negligible, there is the problem of dose-response relationships at the lowest levels: how are the risks (if any) associated with occupational and diagnostic exposure, for example, to be extrapolated from data on heavier exposures? The population sizes needed for proper risk estimates at these low levels are enormous. For example, if risk is proportionate to dose right down to zero-that is, if there is a linear dose-response relationship-and if 1000 exposed and 1000 control subjects are required to estimate the excess cases of cancer caused by 1 Gy (100 rad) of radiation, 100000 in each group would be needed for $0 \cdot 1 \mathrm{~Gy}(10 \mathrm{rad})$ and a million for $0.01 \mathrm{~Gy}(1 \mathrm{rad}) .^{3}$ Moreover, extrapolation is beset with many other problems, such as lack of comparability between different populations and conditions of exposure.

A linear dose-response relationship has been generally assumed in setting radiological protection standards. But this is widely believed to give too high an estimate of the risk of cancers from very low radiation levels, ${ }^{23}$ at least for the low-LET $x$-rays and gamma rays, which are the main radiation types to which the general population and workers are exposed. Some support a quadratic relationship, with the cancer risk proportionate to the square of the radiation dose for $x$-rays and gamma rays: in other words, the risk per unit dose at low levels would then be disproportionately low compared with that at high levels (fig 1). ${ }^{3}$ Nevertheless, certain scientists are arguing that the linear hypothesis actually underestimates the risks. ${ }^{4}$

The recently published third report of the US National

British Medical Journal, London WC1H 9JR

DAPHNE GLOAG, MA, staff editor

\section{Ionising radiation and its measurement}

Radioactivity is energy, in the form of particles or waves, liberated from the nuclei of unstable atoms or artificially by nuclear fission. Some of the atoms of any material in the path of radiation become charged or ionised. Alpha particles and neutrons ionise very intensely and are known as high-linear-energy-transfer (LET) radiation. For a given amount of energy they normally have a higher chance of causing irreparable damage in a cell than low-LET radiation (beta particles, gamma rays, and $x$-rays), which ionises more sparsely; with the latter much of the damage may be made good by the cellular repair processes.

The rad ("radiation absorbed dose") is the conventional measure of the radiation energy actually absorbed, being equivalent to $10^{-2}$ joules per kilogram of irradiated material. In SI units, $100 \mathrm{rad} \equiv 1$ gray (Gy). To take account of the different biological effectiveness of low- and high-LET radiation the rem ("roentgen equivalent for man") is often used. Thus for beta and gamma radiation and $x$-rays $1 \mathrm{rad} \equiv 1 \mathrm{rem}$, but for alpha particles $1 \mathrm{rad} \equiv 10 \mathrm{rem}$. In SI units, $100 \mathrm{rem} \equiv$ 1 sievert (Sv).

Academy of Sciences Committee on the Biological Effects of Ionising Radiation (known as the BEIR report) represents something of a compromise. ${ }^{3}$ The data on irradiated populations are not robust enough, it observes, to discriminate between the different possible dose-response models, and indeed the relationship between dose and effect at very low levels may be impossible to discover statistically. Though preferring, for total cancer risk, a linear-quadratic model (fig 1), which gives estimates intermediate between those based on the linear and the quadratic models, the report presents an "envelope" of estimates; the linear curve provides upper limits (suggested as overestimates) of cancer risk from low-LET radiation and the quadratic curve lower limits (table). For high-LET radiation, however, it concludes that the linear hypothesis is not so likely to give overestimates and may even lead to underestimates. Because of uncertainty about whether the extra cases of cancer at a given dose should be seen as a proportion of the natural cancer incidence in a given population or as a fixed addition, the estimates are expressed both as "relative" and as "absolute" risks. Age at exposure is believed to influence radiosensitivity, and tissues and organs also vary considerably in their sensitivity.

The estimates are lower than those given in the second BEIR report in 1972, partly because of the different assumptions used in the extrapolations but also because epidemiological data have been extended since then. We do not know, the committee concludes, whether absorbed doses up to a few milligray (hundreds of millirad) of low-LET radiation a year are detrimental; but it believes that a few tens of milligray (rad), as in 
occupational exposures, could have a discernible carcinogenic effect. The chief emphasis, however, is laid on the assumptions, procedures, and uncertainties of the estimations rather than specific numbers.

Two members of the BEIR Committee dissented and added minority reports - the disagreements in fact caused a delay in publication of well over a year. Rossi argues that the most plausible estimate of the cancer risk from low-LET radiation is lower than any of the ones given in the report, and that as a corollary dangerous underestimates of the risks from high-LET
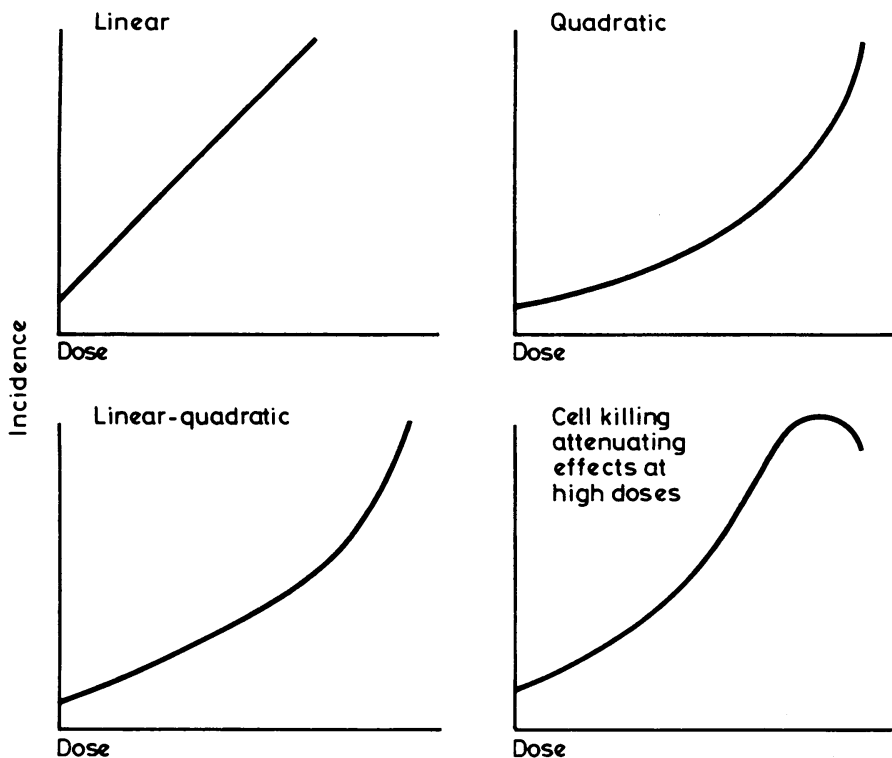

FIG 1-Possible dose-response curves for the relation between cancer incidence and low-LET radiation. (Adapted from fig V-II of The Effects on Populations of Exposure to Low Levels of Ionising Radiation ${ }^{3}$ with the permission of the National Academy of Sciences, Washington DC. attention to evidence on this subject as a new development since its previous report; the epidemiological work of Bross ${ }^{7}$ has been heavily criticised, ${ }^{3}{ }^{8}$ but if increased radiation sensitivity occurs in heterozygotes for DNA repair deficiency conditions, it observes, there could be considerable susceptible groups in the population. ${ }^{3}$

The major cancers induced by whole-body radiation have been established as leukaemia and tumours of the breast in women, the thyroid (especially in women), the lung, and some digestive organs ${ }^{3}$; but approximate risk estimates, at the higher radiation levels, have been derived for at least 10 other organs from more limited data. ${ }^{1}{ }^{9} \mathrm{By}$ and large the cancer risk estimates derived from different epidemiological studies are reasonably consistent-despite the differences in the populations studied and the conditions of radiation exposure. ${ }^{136} 9$ Nevertheless, there are inherent limitations in most studies. Three main categories of radiation exposure have been covered $^{1}$ : nuclear explosions (chiefly at Hiroshima and Nagasaki, but also in the Marshall Islands after a weapon test in 1954 that gave rise to excess thyroid cancers); radiotherapy and diagnostic radiology; and occupation (especially uranium mining and radium luminising). Very long-term follow-up is clearly essential; even now the Japanese life-span study is incomplete.

\section{Evidence from the atomic bomb survivors}

The Japanese data are much the most extensive. Some 284000 survivors, followed up from 1950 to $1974,{ }^{3}$ have received intensive medical surveillance; estimates of the radiation received in each case were based on painstaking reconstructions of the event, ${ }^{10}$ and the widest range of absorbed doses are represented in these populations-right down to $90 \mathrm{mGy}$ (9 rad) and below for the "control" groups. The atomic bomb survivors, however, are recognised to be uncharacteristic of general populations and likely to be highly selected. ${ }^{1}$ Long-term effects were not as common as might have been supposed. ${ }^{1011}$ There were cases of mental handicap and small skull size in children

Estimated excess mortality per million persons from all forms of cancer: single absorbed dose of $0 \cdot 1$ Gy (10 rad) and lifetime absorbed dose of $0.01 \mathrm{~Gy}(1 \mathrm{rad}) / y$ of low-LET radiation*

\begin{tabular}{|c|c|c|c|c|c|}
\hline \multirow{2}{*}{\multicolumn{2}{|c|}{ Dose-response model }} & \multirow{2}{*}{\multicolumn{2}{|c|}{$\begin{array}{c}\begin{array}{c}\text { Absolute-risk } \\
\text { projection }\end{array} \\
\begin{array}{c}\text { Single exposure } \\
(0.1 \mathrm{~Gy})\end{array}\end{array}$}} & \multirow{2}{*}{\multicolumn{2}{|c|}{$\begin{array}{c}\begin{array}{c}\text { Absolute-risk } \\
\text { projection }\end{array} \\
\begin{array}{c}\text { Relative-risk } \\
(0.01 \mathrm{~Gy} / \mathrm{y})\end{array}\end{array}$}} \\
\hline & & & & & \\
\hline $\begin{array}{l}\text { Linear-quadratic } \\
\text { Linear } \\
\text { Quadratic }\end{array}$ & $\begin{array}{l}\text { Normal expectation of } \\
\text { cancer deaths } \\
\text { Excess deaths: No } \\
\% \text { of normal } \\
\text { Excess deaths: No } \\
\% \text { of normal } \\
\text { Excess deaths: No } \\
\% \text { of normal }\end{array}$ & $\begin{array}{r}163800 \\
766 \\
0.47 \\
1671 \\
1.0 \\
95 \\
0.058\end{array}$ & $\begin{array}{r}163800 \\
2255 \\
1 \cdot 4 \\
5014 \\
3 \cdot 1 \\
276 \\
0.17\end{array}$ & $\begin{array}{r}167300 \\
4751 \\
2 \cdot 8 \\
11250 \\
6 \cdot 7 \\
+\end{array}$ & $\begin{array}{r}167300 \\
12920 \\
7 \cdot 7 \\
30520 \\
18 \cdot 2 \\
\dagger\end{array}$ \\
\hline
\end{tabular}
*Adapted from tables V-2 and V-3 of The Effects on Populations of Exposure to Low Levels of Ionising Radiation ${ }^{3}$ with the permission of the National Academy of Sciences, Washington DC. Radford points out that a million people, whether in the general population or models.

models.

radiation might result. ${ }^{5}$ Radford on the other hand supports a linear dose-response relationship, arguing that new evidence strengthens the linear hypothesis ${ }^{6}$ : as particular groups have been followed up for longer periods evidence of cancer risk has increased, effects have been observed at progressively lower doses, and more types of radiation-induced cancer have emerged. Moreover, on theoretical grounds he believes that the linearquadratic relationship is appropriate for leukaemia but not for solid tumours. New lines of evidence have also, he argues, come from experimental studies (see next article); and there have been hints that some groups of the population may be particularly susceptible to cellular damage and to the development of cancer as a result of radiation-a possibility, says Radford, that justifies a slight overestimation of risk for the population as a whole. The BEIR Committee itself draws irradiated in utero but no detectable excess of genetic defects or childhood cancers in the offspring of exposed parents. There was also a significantly lower death rate than expected for causes other than malignancy. Rotblat claims that there has been a greater excess of certain tumours in the other irradiated populations than in the Japanese-for lung cancer, for instance, a six-fold greater excess. ${ }^{11}$ The excess for leukaemia, however, is equivalent in the Japanese and the other data.

One possibility-if the differences are genuine rather than effects of non-comparable populations, etc-is that the survivors of Hiroshima and Nagasaki, selected by their ability to survive the immediate trauma caused by the bombs, were unusually resistant to cancer. Rotblat further argues that a greater excess of leukaemia would in fact have been expected than in other irradiated groups, on the grounds that whole-body irradiation, 
to which the Japanese were exposed, may have a disproportionately greater effect than the partial-body irradiation received by most other groups." $\mathrm{He}$ has also argued from the experience of the "early entrants" to the bombed cities, who were not "selected" and though exposed to much lower levels of radiation appeared to have a relatively higher risk of leukaemia. ${ }^{12}$ On this basis Rotblat estimates 160 extra cases of leukaemia per

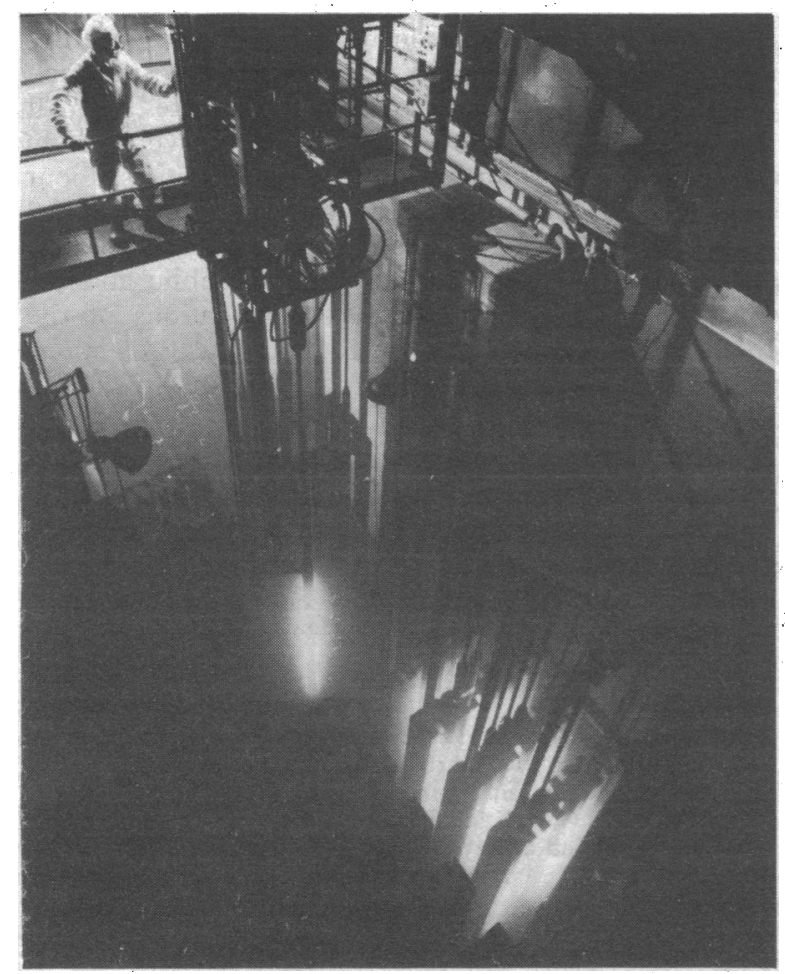

FIG 2-Fuel storage pond, steam-generating heavy water reactor, AEE Winfrith, Dorset: Cerenkov radiation from irradiated fuel. (Reproduced by courtesy of the United Kingdom Atomic Energy Authority.)

million people receiving $10 \mathrm{mSv}$ ( $1 \mathrm{rem}$ ), in contrast to the figure of 30 per million per $10 \mathrm{mSv}$ for the inhabitants and the other irradiated groups.

The speculation about the early entrants is dismissed by many authorities as not founded on adequate data..$^{13}$ Moreover, for lung cancer particularly we have other possible explanations why data on the Japanese populations might yield artificially low radiation risk factors. ${ }^{1}$ Furthermore, does resistance to cancer necessarily go with the ability to survive trauma? The validity of the Japanese risk estimates has, however, also been questioned on the grounds that a population that has received "tissue-destructive" doses of radiation is not suitable for deriving risk estimates for low doses-since many of those who might have died of cancers will have succumbed to the long-term effects of bone marrow depression before cancers had time to develop. ${ }^{14}$

\section{Data from medically irradiated groups}

Extensive follow-up studies have been carried out in patients receiving therapeutic and repeated diagnostic irradiation, usually at moderate or high doses. ${ }^{1} \rightarrow$ For example, risk estimates for leukaemia have come from patients treated for ankylosing spondylitis ${ }^{15} 16$ and from children irradiated in utero, ${ }^{17}$ and for thyroid cancer from children with tinea capitis who received an average dose to the thyroid of only $65 \mathrm{mGy}$ $(6.5 \mathrm{rad}){ }^{18}$

Medically irradiated groups have been particularly informative about the risks of breast cancer, especially as age-specific risk estimates are now available and are claimed to be similar in all the groups and also the atomic bomb survivors. ${ }^{19}$ The "medical" groups consist mainly of tuberculous women who had repeated fluoroscopic examinations of the chest during pneumothorax treatment and women given radiotherapy for postpartum mastitis. Taken with the Japanese data, a wide range of doses is covered. The risk is held to be consistent with a linear dose-response relationship and inconsistent with any relationship diverging widely from the linear. ${ }^{10}$ It appears to be little affected by fractionation of the radiation dose and to have been similar in Hiroshima (where there was a strong component of high-LET radiation) and Nagasaki (mainly low-LET radiation). Such similarities of risk suggest that breast cancer is induced by a single ionising event or "hit," which would give added weight to the theory of proportionate risks. Those who do not support a linear relationship in general accept that breast cancer may have a different mechanism, with a stronger influence of other factors than in other radiationinduced cancers. Age at exposure seems to be particularly important, the age group 10-19 years having the highest risk. ${ }^{19}$

Reviewing the various studies on high-level and fairly lowlevel medical irradiation, Brown suggests that there may even be a greater proportionate risk (per unit dose) at low than at high doses for breast cancer, leukaemia, and thyroid cancer. ${ }^{20}$

Studies of patients receiving smaller diagnostic $x$-ray doses have given varied results. A recent survey of leukaemia in relation to diagnostic radiology found no evidence of increased risk, though numbers were small and the study has been criticised. ${ }^{21} 22$

\section{Some occupational studies}

Among occupational groups, the 1000 women in Britain who worked with radium as painters of luminous dials are particularly useful: they received an average of about $0.4 \mathrm{~Sv}(40 \mathrm{rem})$ at dose rates of $50-200 \mathrm{mSv}(5-20 \mathrm{rem})$ a year from external radiation, and in most cases their exposure ceased over 30 years ago. Even so only about 200 have died and firm conclusions would be premature. Only one has died from leukaemia, the number expected from national statistics; if the risk from radiation is even 10 times greater than the official estimate of 20 cases per million per $10 \mathrm{mSv}$ eight more of these women should have been affected. ${ }^{23}$ The only malignancy showing an excess so far is breast cancer-in women who were under 30 while working with radium (J Vennart, personal communication). Again there seems to be a roughly linear dose-response relationship by comparison with data on heavily irradiated women.

Debate continues about the Mancuso study, based on records from the Hanford plutonium processing plant in the United States. ${ }^{24}{ }^{25}$ The analyses were claimed to give estimates of cancer risk 10-20 times higher than the conventional ones. Criticism has centred on the statistical methods ${ }^{26}{ }^{27}$; an excess in the radiation workers of cancer of the pancreas, multiple myeloma, and possibly lung cancer remained after reanalysis of the data, but this was thought to be an unlikely pattern for radiation-induced cancers and more plausibly ascribed to other causes. A different approach to the data by an independent worker, however, gave some results that were consistent with those of the Mancuso study, though confidence limits were wide. $^{28}$ Now the original authors have returned to the fray replying to the criticisms. ${ }^{14}$

An apparent excess of cases of leukaemia among nuclear shipyard workers ${ }^{29}$ disappears in the light of further information obtained by the authors of the study. ${ }^{3} \mathrm{~A}$ small study in nuclear dockyard workers showed an increase in chromosome abnormalities that increased linearly with radiation exposure, but the significance of these changes is not known. ${ }^{30}$ An apparent excess of leukaemia cases was found among men who had taken part in military manoeuvres at a nuclear bomb test-the highest gamma-ray dose in the nine patients being about $30 \mathrm{mSv}$ ( 3 rem); but there are many reservations about this preliminary study. ${ }^{30 a}$ 
The Medical Research Council is supporting a study of about 30000 past employees of the United Kingdom Atomic Energy Authority; this should be complete in 1982.

\section{Some studies relating to very low-level radiation exposure}

Nuclear waste gives rise to radiation exposures in the population well below those discussed above. A recent American report from Colorado State attracted much attention-it claimed a cancer incidence $24 \%$ higher in the men and $10 \%$ higher in the women exposed to plutonium-containing exhaust fumes from a plutonium processing plant (apparently resulting in soil contamination) than in the control population (CJ Johnson, paper to International Radiation Protection Association, Jerusalem, 1980). The paper has, however, been heavily criticised (J A Reissland and S C Darby, NRPB, unpublished paper). An apparent increase in registrations of myeloid leukaemia in Lancashire, ${ }^{31}{ }^{32}$ it has been suggested, might be associated with the increased radioactivity of the coastal waters and fish in North-west England; but this now seems unlikely. ${ }^{23} 33$

If very low-level radiation does damage cells, areas of the world with high natural radioactivity might be expected to produce long-term effects on their populations; but no good evidence of these have so far emerged. ${ }^{3}$ Effects would, however, be hard to prove, since there is generally no more than a twofold difference in radiation dose between the areas with high and low background levels, and huge populations would be needed; in any case differences in other factors are likely that would mask any small radiation effect. A recent Chinese study covered a stable population of about 73500 in areas with background radiation some three times that of the control areas, but this too failed to uncover any health effects. ${ }^{34}$

The extensive data from the various lengthy studies from which the International Commission on Radiological Protection derives its recommended dose limits would appear to give a reasonably sound and consistent basis. Nevertheless the uncertainties about very low radiation levels are sufficient for studies giving divergent results to have serious attention. Theoretical considerations will be looked at briefly in the next article, to introduce some discussion of the practical issues.

I am grateful for helpful discussion with Professor J Rotblat and with Dr J Vennart, director of the Medical Research Council Radiobiology Unit; and for generous help with information and reports from the National Radiological Protection Board.

\section{References}

1 United Nations Scientific Committee on the Effects of Atomic Radiation. Sources and effects of ionising radiation. New York: United Nations, 1977.

2 International Commission on Radiological Protection. Publication No 26. Oxford: Pergamon Press, 1977.

3 BEIR Committee. The effect on populations of exposure to low levels of ionising radiation. Third report. Washington: National Academy of Sciences, 1980.

4 Washington Congressional Environmental Study Conference. Radiation standards and public safety. Proceedings of the second congressional seminar on low-level ionising radiation, 1978. Washington: 1979.

${ }^{5}$ Rossi H. In: BEIR Committee. The effect on populations of exposure to low levels of ionising radiation. Third report. Washington: National Academy of Science, 1980.

${ }^{6}$ Radford E. In: BEIR Committee. The effect on populations of exposure to low levels of ionising radiation. Third report. Washington: National Academy of Sciences, 1980.

' Bross IDJ, Ball M, Falen S. A dosage response curve for the one rad range: adult risks from diagnostic radiation. Am 7 Publ Hlth 1979;69: 130-6.

${ }^{8}$ Boice JD, Land CE. Adult leukaemia following diagnostic $x$-rays ? Am $\mathcal{F}$ Publ Hlth 1979;69:137-45.

${ }^{9}$ Pochin EE. Risk assessment for radiation protection purposes. International Atomic Energy Bulletin (in press)

${ }^{10}$ Morgan C. Hiroshima, Nagasaki, and the RERF. Am $\mathcal{F}$ Pathol 1980;98: 843-53.

11 Rotblat J. The puzzle of absent effects. New Scientist 1977;75:475-6.

\section{Sources of radiation and radiological protection}

Natural radiation consists of cosmic rays, radiation from rocks and soil, and internal naturally occurring radionuclides, and contributes by far the most to the average exposure in any community-about two-thirds of the whole-body dose. This is followed by medical irradiation, which constitutes nearly a third of the total for the British population taken as a whole. Fallout, radiation from consumer products and other miscellaneous sources, and occupational exposure each provide under $1 \%$, and radioactive waste a small fraction of $1 \% .^{35} 36$ The average annual whole-body dose equivalent from all sources in Britain is about $1600 \mu \mathrm{Sv}$ (160 mrem) according to the National Radiological Protection Board. ${ }^{32}$ National radiological protection standards, for the general public and for workers, are based on the recommendations of the International Commission on Radiological Protection; the current recommendations are set out in ICRP Publication $26 .^{2}$

12 Rotblat J. The risks for radiation workers. Bulletin of the Atomic Scientists September 1978:41-6.

${ }^{13}$ Mole R. Radiation risks-a rejoinder. New Scientist 1979;82:440.

14 Stewart A, Kneale G, Mancuso T. The Hanford data-a reply to recent criticisms. Ambio 1980;9:66-73.

15 Court Brown WM, Doll R. Leukaemia and aplastic anaemia in patients irradiated for ankylosing spondylitis. Medical Research Council Special Report Series. No 295. London: HMSO, 1957.

16 Court Brown WM, Doll R. Mortality from cancer and other causes after radiotherapy for ankylosing spondylitis. $\mathrm{Br}$ Med $\mathcal{f} 1965 ; \mathrm{ii}: 1327-32$.

17 Stewart A, Kneale GW. Radiation dose effects in relation to obstetric $x$-rays and childhood cancers. Lancet 1970 ; i:1185-8.

18 Modan, B, Baidatz D, Mart H, Steinitz R, Levin SG. Radiation-induced head and neck tumours. Lancet $1974 ; \mathrm{i}: 277-9$.

19 Land CE. Low-dose radiation-a cause of breast cancer? Cancer 1980; $46: 868-73$.

${ }^{20}$ Brown JM. Linearity vs non-linearity of dose response for radiation carcinogenesis. Health Physics 1976;31:231-45.

${ }^{21}$ Linos A, Gray JE, Orvis AL, Kyle RA, O'Fallon M, Kurland LT. Low-dose radiation and leukemia. N Engl f Med 1980;302:1101-5.

22 Jablon S; Preston-Martin S, Pike MC; Bross IDJ; Rothman KJ; Linos A, et al [separate letters]. Low-dose radiation and leukemia. $N$ Engl f Med $1980 ; 302: 814-6$

${ }^{23}$ Baverstock KF, Papworth DG, Vennart J. Incidence of myeloid leukaemia in Lancashire. Lancet 1979 ;ii:1362-3.

${ }^{24}$ Mancuso TF, Stewart A, Kneale G. Radiation exposure of Hanford workers dying from cancer and other causes. Health Physics $1977 ; 33$ : 369-85.

${ }^{25}$ Kneale GW, Stewart AM, Mancuso TF. Re-analysis of data relating to the Hanford study of the cancer risks of radiation workers. In: Late biological effects of ionising radiation. Vol 1. Vienna: International Atomic Energy Agency, 1978.

${ }^{26}$ Anderson TW. Radiation exposures of Hanford workers: a critique of the Mancuso, Stewart, and Kneale report. Health Physics 1978;35 743-50.

${ }^{27}$ Reissland JA. An assessment of the Mancuso study. NRPB-R79. Harwell: National Radiological Protection Board, 1978.

${ }^{28}$ Goffman JW. The question of radiation causation of cancer in Hanford workers. Health Physics 1979;37:617-39.

${ }^{29}$ Najarian T, Colton T, Mortality from leukaemia and cancer in shipyard nuclear workers. Lancet $1978 ; \mathrm{i}: 1018-20$.

30 Evans HJ, Buckton KE, Hamilton GE, Carothers A. Radiation-induced chromosome aberrations in nuclear-dockyard workers. Nature 1979; 277:531-4.

30a Caldwell GG, Kelley DB, Heath CW jr. Leukemia among participants in military maneuvers at a nuclear bomb test. A preliminary report. fAMA 1980;244:1575-8 (with editorial).

${ }^{31}$ Geary CG, Benn RT, Leck I. Incidence of myeloid leukaemia in Lancashire. Lancet $1979 ;$ ii:549-51.

${ }^{32}$ Leck I, Benn RT, Smith A. Changes in myeloid leukaemia incidence? Lancet 1980 ;ii:749-50.

${ }^{33}$ Kemp IW, Stein GJ, Hessman MA. Myeloid leukaemia in Scotland. Lancet 1980;ii:732-4.

${ }^{34}$ High Background Radiation Research Group. Health survey in high background radiation areas in China. Science 1980;209:877-80.

35 Taylor FE, Webb GAM. Radiation exposure of the UK population. NRPB-R77, Harwell: National Radiological Protection Board, 1978.

${ }^{36}$ Taylor F, Webb G. Where does radiation come from? New Scientist 21/28 December 1978:922-3. 